\title{
Risk group of AIS is the key to its prophylaxis
}

\author{
Mikhail Dudin ${ }^{1 *}$, Dmitry Pinchuk ${ }^{1}$, Viktor Pechersky ${ }^{2}$, Tatyana Avaliany ${ }^{3}$, Tatyana Khaymina ${ }^{1}$, Aleksei Shashko ${ }^{1}$
}

From The 10th Meeting of the International Research Society of Spinal Deformities (IRSSD 2014 Sapporo)

Sapporo, Japan. 29 June - 2 July 2014

\section{Introduction}

One of the fundamental properties of typical AIS is its monomorphism. The C-shaped scoliosis is a "pure" 3D deformation, while S-shaped form consists of two 3D curves, etc. Mathematical modeling has shown a steady sequence of forming units of 3D deformation. Real clinical manifestations in the initial period of development of typical AIS are identical to changes, predicted by mathematical modeling on the basis of identified consistent patterns.

\section{Objectives}

To define the sequence of clinical symptoms and their importance in the transition of a healthy spinal column to "scoliotic" one, that will determine criteria for risk group. It allows us to develop a treatment at the preclinical stage of typical AIS, that is the basis for its prophylaxis.

\section{Material and methods}

During 2012-2013 we observed 600 children of both sexes, aged 9 to 13 years, residing in one settlement.

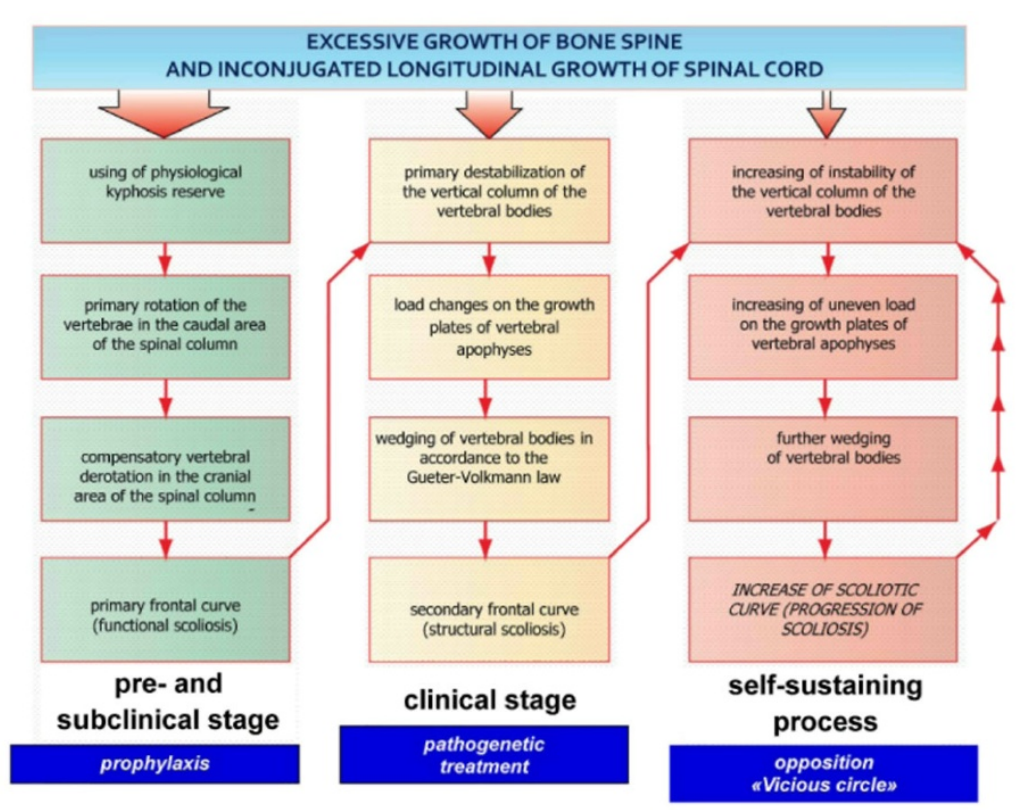

Figure 1 Pathogenesis of AIS

${ }^{1}$ Children's Rehabilitation Center of Orthopedics and Traumatology

"Ogonyok", Russia

Full list of author information is available at the end of the article

C 2015 Dudin et al; licensee BioMed Central Ltd. This is an Open Access article distributed under the terms of the Creative Commons Attribution License (http://creativecommons.org/licenses/by/4.0), which permits unrestricted use, distribution, and reproduction in any medium, provided the original work is properly cited. The Creative Commons Public Domain Dedication waiver (http:// 

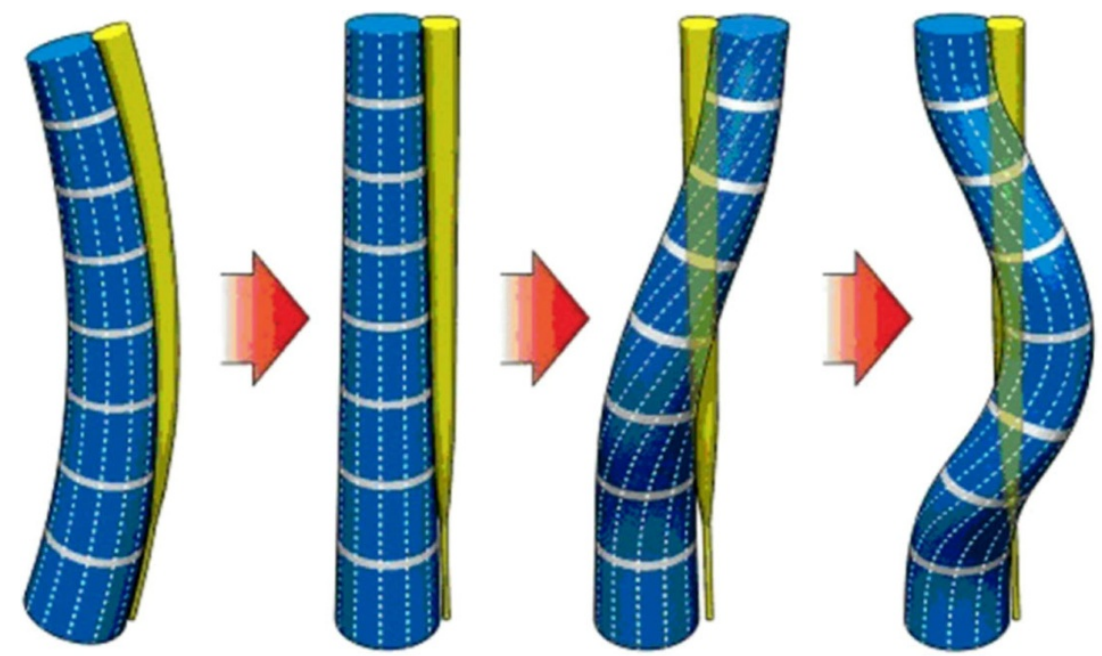

Figure 2 Transformation of healthy spinal column in scoliotic one (sagittal profile)

The group included children without signs of AIS. During this period physical and instrumental examination of all these children were carried out every 8-12 months. The instrumental examination included: CDOT, EMG, stabilometry and immunoferment analysis of neuropeptides (oxytocin and arginine-8-vasopressine) level, as posture asymmetry factor.

\section{Results}

1. The AIS pathogenesis has been clarified on the basis of obtained data (see Figure 1).

2. The following sequence of clinical symptoms at risk group of typical AIS was defined: normal spine $\rightarrow$ fatback (sagittal plane) $\rightarrow$ flat-back + torsion of all trunk from spine lumbar zone (the first stage of horizontal plane. See Fig. 2). It is the pre-clinical development of the typical AIS (risk group of typical AIS).

But "flat-back + torsion of spine lumbar zone" leads to detorsion of the shoulder girdle or upper part of the trunk (the second stage of horizontal plane). The projection of the spinal canal is straight (not deformed), while in the column of vertebral bodies can be seen two "anticircuits" (opposite direction twisting), which finish the emergence of $3 \mathrm{D}$ deformation. It is the beginning of the clinical development of the typical AIS.

3. The obtained data of instrumental examinations were completely identical to described above sequence of clinical symptoms. The greatest interest was aroused by the results of neuropeptides investigation. The altering of their levels was observed even at the end of fatback formation.

\section{Conclusion}

On the basis of obtained data the complex of therapeutical interventions was created to prevent typical AIS. Currently the clinical testing of this complex is carried out in a representative group of the child population and preliminary results (only for 2013) are encouraging.

\section{Authors' details}

${ }^{1}$ Children's Rehabilitation Center of Orthopedics and Traumatology "Ogonyok", Russia. ${ }^{2}$ Child's Orthopedics Center "Rodnik", Russia. Institute of experimental medicine of the North-West Branch of the Russian Academy of Medical Sciences, St. Petersburg, Russia.

Published: 19 January 2015

doi:10.1186/1748-7161-10-S1-P10

Cite this article as: Dudin et al:: Risk group of AIS is the key to its prophylaxis. Scoliosis 2015 10(Suppl 1):P10.

\section{Submit your next manuscript to BioMed Central} and take full advantage of:

- Convenient online submission

- Thorough peer review

- No space constraints or color figure charges

- Immediate publication on acceptance

- Inclusion in PubMed, CAS, Scopus and Google Scholar

- Research which is freely available for redistribution 